\title{
Triangular Resection of the Upper Lateral Cartilage for Middle Vault Deviation
}

\author{
Gwanghui Ryu · Min Young Seo · Kyung Eun Lee · Sang Duk Hong · Seung-Kyu Chung · Hun-Jong Dhong · Hyo Yeol Kim \\ Department of Otorhinolaryngology-Head and Neck Surgery, Samsung Medical Center, Sungkyunkwan University School of Medicine,
}

Seoul, Korea

Objectives. Middle vault deviation has a significant effect on the aesthetic and functional aspects of the nose, and its management continues to be a challenge. Spreader graft and its modification techniques have been focused, but there has been scarce consideration for removing surplus portion and balancing the upper lateral cartilage (ULC). This study aimed to report the newly invented triangular-shaped resection technique ("triangular resection") of the ULC and to evaluate its efficacy for correcting middle vault deviation.

Methods. A retrospective study included 17 consecutive patients who presented with middle vault deviation and underwent septorhinoplasty by using triangular resection at a tertiary academic hospital from February 2014 and March 2016. Their outcomes were evaluated pre- and postoperatively including medical photographs, acoustic rhinometry and subjective nasal obstruction using a 7-point Likert scale.

Results. The immediate outcomes were evaluated around 1 month after surgery, and long-term outcomes were available in 12 patients; the mean follow-up period was 9.1 months. Nasal tip deviation angle was reduced from $5.66^{\circ}$ to $2.37^{\circ}$ immediately $(P<0.001)$. Middle vault deviation also improved from $169.50^{\circ}$ to $177.24^{\circ}(P<0.001)$. Long-term results were $2.49^{\circ}(P=0.015)$ for nasal tip deviation and $178.68^{\circ}(P=0.002)$ for middle vault deviation. The aesthetic outcome involved a complete correction in eight patients $(47.1 \%)$, a minimally visible deviation in seven patients $(41.2 \%)$ and a remaining residual deviation in two patients $(11.8 \%)$. Pre- and postoperative minimal cross-sectional areas (summation of the right and left sides) were 0.86 and 1.07 , respectively $(P=0.021)$. Fifteen patients answered about their nasal obstruction symptoms and the median symptom score had alleviated from 6.0 to $3.0(P=0.004)$.

Conclusion. Triangular resection of the ULC is a simple and effective method for correcting middle vault deviation and balancing the ULCs without complications as internal nasal valve narrowing.

Keywords. Rhinoplasty; Nose; Acquired Nasal Deformities; Nasal Cartilages

\section{INTRODUCTION}

Middle vault deviation of the nose is composed of the upper lateral cartilage (ULC) and nasal septum, and it has a significant effect on the aesthetic and functional aspects of the nose. The

\footnotetext{
- Received December 22, 2017

Revised March 3, 2018

Accepted March 29, 2018

- Corresponding author: Hyo Yeol Kim

Department of Otorhinolaryngology-Head and Neck Surgery, Samsung

Medical Center, Sungkyunkwan University School of Medicine,

81 Irwon-ro, Gangnam-gu, Seoul 06351, Korea

Tel: +82-2-3410-3579, Fax: +82-2-3410-3879

E-mail: siamkhy@gmail.com
}

ULC is a part of the internal nasal valve, which is important to the nasal airway and can cause the functional problem of nasal obstruction [1,2]. There are two important concepts for correcting a deviated nose. First, straightening of the nasal septum and balancing the asymmetric structure of the nose [3]. Before surgery, the most important aspect is to identify the anatomic cause of the deviation. A nose with middle vault deviation usually involves asymmetry of both ULCs. The second aspect is to correct the septum or bony vault asymmetry prior to fixing middle vault deviation.

Many surgical techniques that concentrate on the ULC to correct middle vault deviation have been reported. Camouflage or onlay grafts are performed for mild deviations, while spreader

Copyright $\odot 2018$ by Korean Society of Otorhinolaryngology-Head and Neck Surgery.

This is an open-access article distributed under the terms of the Creative Commons Attribution Non-Commercial License (http://creativecommons.org/licenses/by-nc/4.0)

which permits unrestricted non-commercial use, distribution, and reproduction in any medium, provided the original work is properly cited. 
grafts or clocking sutures are used for severe deviations $[4,5]$. However, straightening the middle third of the dorsum is surgically quite challenging, and these methods still have limitations.

If the size of the ULC still affects middle vault deviation after correcting other parts, resection and balancing of the larger side of cartilage should be considered as an additional technique for correcting the deviation. We call this approach triangular resection of the ULC. We aimed to report a series of 17 cases using the newly invented triangular resection technique of the ULC and to evaluate the effect of this procedure for correcting middle vault deviation.

\section{MATERIALS AND METHODS}

\section{Participants}

Seventeen consecutive patients were enrolled between February 2014 and February 2016 in this retrospective single-center study. Fifteen were Korean and two were Caucasian. Patients presented with middle vault deviation and underwent septorhinoplasty by the senior author (HYK) in the Otorhinolaryngology Department of a tertiary academic hospital. This study protocol was approved by the Samsung Medical Center Institutional Review Board (IRB No. SMC 2016-10-092) and the informed consents were waived.

\section{Surgical details}

The triangular resection technique was planned if patient had middle vault deviation with or without deviation of the bony dorsum. Otherwise during the surgery, we firstly corrected bony deviation using osteotomies and residual deviation of cartilaginous dorsum was corrected with triangular resection of asymmetric ULC. In some cases of revision surgery or in patients with trauma history, triangular resection had not planned because of the difficulty of dissecting cartilages.

All patients underwent open approach septorhinoplasty via an inverted-V incision. Septoplasty was firstly performed using customized procedures depending on the individual status of nasal septum. We performed "modified mattress suture technique" in three patients who had high bony deviation and the technique was invented by the corresponding author of this study [6]. After septoplasty and correction of the bony deviation

\section{H I G H L I G H T S}

- Triangular resection of the upper lateral cartilage is an additive surgical option for correcting middle vault deviation and it is a very simple and timesaving method.

- After removing surplus portion of the upper lateral cartilage, there was no influence on the dorsal width and no internal valve narrowing.
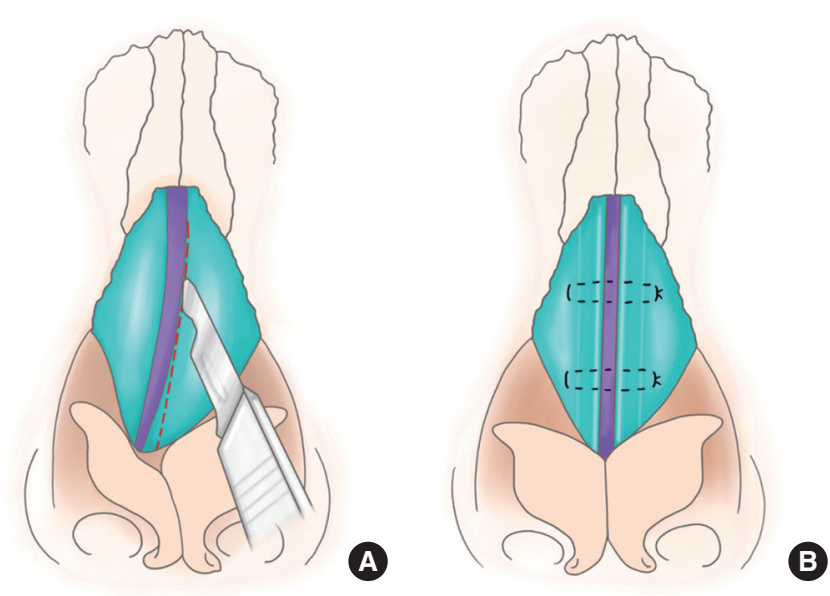

Fig. 1. Surgical methods of triangular resection of the upper lateral cartilage. (A) Resect the triangular-shaped surplus cartilage. (B) The septum and the upper lateral cartilage repair with horizontal mattress sutures.

or hump nose with various procedures with osteotomy (lateral, medial, and/or intermediate) and/or humpectomy, triangular resection of the ULC was performed as follows: first, separate the septum and longer side of the ULC. Second, push the nasal septum to the midline to estimate the surplus portion of the ULC and resect the triangular-shaped surplus cartilage with blade or iris scissors. Caudal part of the ULC was removed 3-mm width in average. During this procedure, the removed portion of the ULC should be narrow in the cephalic part and wide in the caudal region. Finally, the septum and the ULC must be repaired with horizontal mattress sutures using 4-0 polydioxanone (Ethicon, Somerville, NJ, USA) (Fig. 1).

\section{Evaluation}

Nasal tip deviation and middle vault deviation were measured on facial photographs according to previously reported methods using a protractor [7-9]. Nasal tip deviation was assessed at an angle between the nasal tip and midline from the nasion to the philtrum. Middle vault deviation was defined as an angle of the nasion, the most prominent point of convexity of the middle vault, and the nasal tip (Fig. 2).

Two independent surgeons who were not involved in this study used the pre- and postoperative photographs to evaluate the degree of dorsal deviation without any information about the surgery itself. The results were assessed with a scale composed of complete correction, minimally visible deviation or remaining residual deviation [10].

Patients also underwent acoustic rhinometry (AR-1003; Hood Laboratories, Pembroke, MA, USA) before and after surgery, and the minimal cross-sectional area (MCA) was evaluated to estimate the improvement of the nasal dimension. A survey for subjective nasal obstruction was also conducted using a 7-point Likert scale (1, no obstruction; 7, very severe obstruction). 

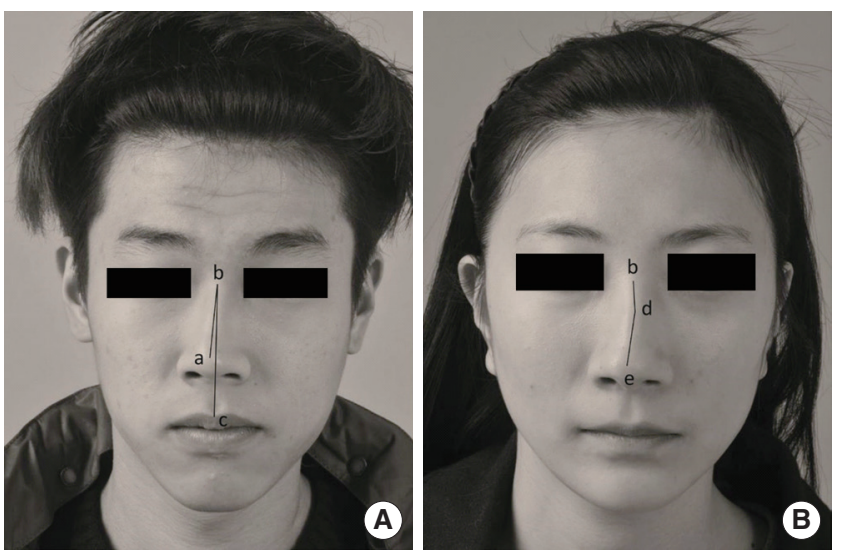

Fig. 2. Measurement of nasal tip deviation and middle vault deviation. (A) Nasal tip deviation was measured between the nasal tip (a) and midline from the nasion (b) to the philtrum (c). (B) Middle vault deviation was measured as the angle of the nasion (b), the most prominent point of convexity of the middle vault (d), and the nasal tip (e).
Data were tested for normality of distribution using the Shapiro-Wilk test and all data was not normally distributed which presented as median and interquartile range. We analyzed these parameters with the Wilcoxon signed-rank test and the MannWhitney $U$-test. Data were expressed as median and interquartile range. The $P$-values of $P<0.05$ were used to determine significance throughout the analysis.

\section{RESULTS}

The mean age was 30.1 years (range, 18 to 49 years), and 12 patients were male $(70.6 \%)$. Fifteen patients were Korean, and two patients were Caucasian (one male and one female). The mean follow-up period of 17 patients was 6.6 months. Immediate postoperative results were evaluated with the first postoperative photograph and the average time taken for first photography was about 3 weeks after surgery. Long-term results were

Table 1. Demographic data of the patients

\begin{tabular}{|c|c|c|c|c|c|c|c|c|c|}
\hline \multirow{2}{*}{ No. } & \multirow{2}{*}{ Sex } & \multirow{2}{*}{$\begin{array}{l}\text { Age } \\
(y r)\end{array}$} & \multirow{2}{*}{ Ethnicity } & \multicolumn{2}{|c|}{ Follow-up (day) } & \multirow{2}{*}{$\begin{array}{l}\text { Septal } \\
\text { deviation }\end{array}$} & \multirow{2}{*}{$\begin{array}{l}\text { Bony } \\
\text { deviation }\end{array}$} & \multirow{2}{*}{$\begin{array}{l}\text { Hump } \\
\text { nose }\end{array}$} & \multirow{2}{*}{ Surgical technique } \\
\hline & & & & Immediate & Long-term & & & & \\
\hline 1 & Female & 23 & East Asian & 35 & 823 & Left & No & Yes & $\begin{array}{l}\text { Lateral/medial osteotomy, dorsum augmentation, septal } \\
\text { extension graft, cap graft, interdomal/intradomal } \\
\text { suture }\end{array}$ \\
\hline 2 & Male & 20 & East Asian & 31 & - & Left & Yes & Yes & $\begin{array}{l}\text { Lateral/medial osteotomy, humpectomy, radix and dorsum } \\
\text { augmentation, septal extension graft, interdomal/ } \\
\text { intradomal suture }\end{array}$ \\
\hline 3 & Male & 24 & East Asian & 29 & 185 & Left & Yes & No & $\begin{array}{l}\text { Lateral/medial osteotomy, dorsum augmentation, } \\
\text { columellar strut, interdomal/intradomal suture }\end{array}$ \\
\hline 4 & Female & 21 & East Asian & 31 & 634 & Left & No & Yes & $\begin{array}{l}\text { Lateral/medial osteotomy, humpectomy, supratip } \\
\text { augmentation, cap graft, shield graft, columellar strut }\end{array}$ \\
\hline 5 & Male & 22 & East Asian & 15 & 64 & Straight & No & Yes & $\begin{array}{l}\text { Humpectomy, radix/supratip augmentation, columellar } \\
\text { strut, interdomal/intradomal suture }\end{array}$ \\
\hline 6 & Female & 36 & Caucasian & 8 & - & Right & No & No & $\begin{array}{l}\text { Dorsum augmentation, cephalic resection, septal } \\
\text { batten graft, interdomal/intradomal suture }\end{array}$ \\
\hline 7 & Male & 49 & East Asian & 9 & - & Left & No & No & Supratip augmentation, cephalic resection \\
\hline 8 & Male & 38 & East Asian & 8 & 352 & Right & Yes & No & $\begin{array}{l}\text { Lateral/medial osteotomy, columellar strut, interdomal/ } \\
\text { intradomal suture }\end{array}$ \\
\hline 9 & Male & 25 & East Asian & 36 & 211 & S-shape & No & Yes & $\begin{array}{l}\text { Humpectomy, dorsum augmentation, septal extension } \\
\text { graft, cap graft, interdomal/intradomal suture }\end{array}$ \\
\hline 10 & Male & 40 & Caucasian & 9 & 44 & Right & Yes & Yes & $\begin{array}{l}\text { Lateral/medial osteotomy, humpectomy, cap graft, } \\
\text { columellar strut, interdomal/intradomal suture }\end{array}$ \\
\hline 11 & Female & 18 & East Asian & 10 & - & S-shape & Yes & No & $\begin{array}{l}\text { Lateral/medial/intermediate osteotomy, dorsum } \\
\text { augmentation, cap graft, columellar strut }\end{array}$ \\
\hline 12 & Male & 38 & East Asian & 10 & 268 & S-shape & No & No & $\begin{array}{l}\text { Dorsum augmentation, cephalic resection, interdomal/ } \\
\text { intradomal suture }\end{array}$ \\
\hline 13 & Male & 18 & East Asian & - & 218 & Right & Yes & Yes & $\begin{array}{l}\text { Lateral/medial/intermediate osteotomy, humpectomy, } \\
\text { dorsum augmentation, columellar strut }\end{array}$ \\
\hline 14 & Male & 33 & East Asian & 39 & 304 & Left & No & No & $\begin{array}{l}\text { Supratip augmentation, columellar strut, interdomal/ } \\
\text { intradomal suture }\end{array}$ \\
\hline 15 & Female & 29 & East Asian & 30 & - & Left & No & Yes & $\begin{array}{l}\text { Lateral/medial osteotomy, humpectomy, dorsum } \\
\text { augmentation, cephalic resection, septal extension } \\
\text { graft, cap graft, shield graft, }\end{array}$ \\
\hline 16 & Male & 44 & East Asian & 44 & 107 & Right & Yes & No & $\begin{array}{l}\text { Lateral/medial osteotomy, supratip augmentation, } \\
\text { columellar strut }\end{array}$ \\
\hline 17 & Male & 33 & East Asian & - & 78 & Left & No & No & Cap graft, columellar strut \\
\hline
\end{tabular}


Table 2. Immediate and long-term results of nasal tip deviation and middle vault deviation after septorhinoplasty with triangular resection

\begin{tabular}{lccccc}
\hline Variable & Preoperative & Immediate result & $P$-value & Long-term result & $P$-value \\
\hline Nasal tip deviation $\left(^{\circ}\right)$ & $5.66(4.03-6.75)$ & $2.37(1.91-2.81)$ & $<0.001$ & $2.49(0.80-3.91)$ & 0.015 \\
Middle vault deviation $\left(^{\circ}\right)$ & $169.50(165.99-172.82)$ & $177.24(174.89-178.34)$ & $<0.001$ & $178.68(175.78-178.98)$ & 0.002 \\
\hline
\end{tabular}

Values are presented as median (interquartile range). A $P$-value $<0.05$ was considered statistically significant for all analyses.
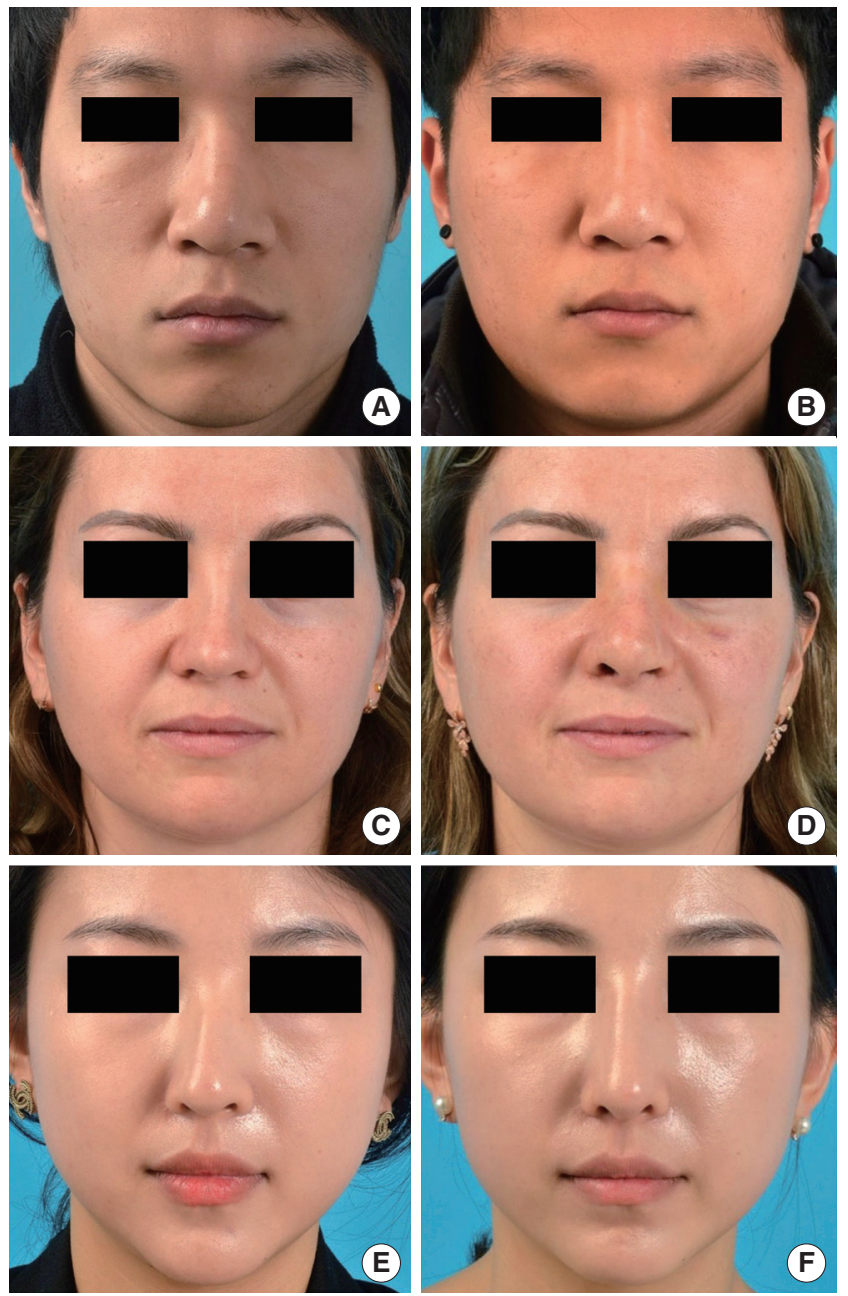

Fig. 3. Pre- and postoperative photographs of three patients. Preand postoperative photograph of patient $3(A, B)$, patient $6(C, D)$, and patient 15 (E, F).

available in 12 patients and two patients had only long-term results; the mean follow-up period of 12 patients was 9.1 months. Two revision rhinoplasty cases were included. Four patients had bony vault deviations; another five patients had hump noses, and three patients suffered from both. Ten patients underwent lateral and medial osteotomies of the nasal bone (Table 1).

Nasal tip deviation angle was immediately reduced from $5.66^{\circ}$ $\left(4.03^{\circ}-6.75^{\circ}\right)$ to $2.37^{\circ}\left(1.91^{\circ}-2.81^{\circ}\right)(P<0.001)$. Middle vault deviation was also improved from $169.50^{\circ}\left(165.99^{\circ}-172.82^{\circ}\right)$ to $177.24^{\circ}\left(174.89^{\circ}-178.34^{\circ}\right)(P<0.001)$. The ideal angle for nasal tip deviation is $0^{\circ}$ and middle vault deviation is $180^{\circ}$. Therefore,
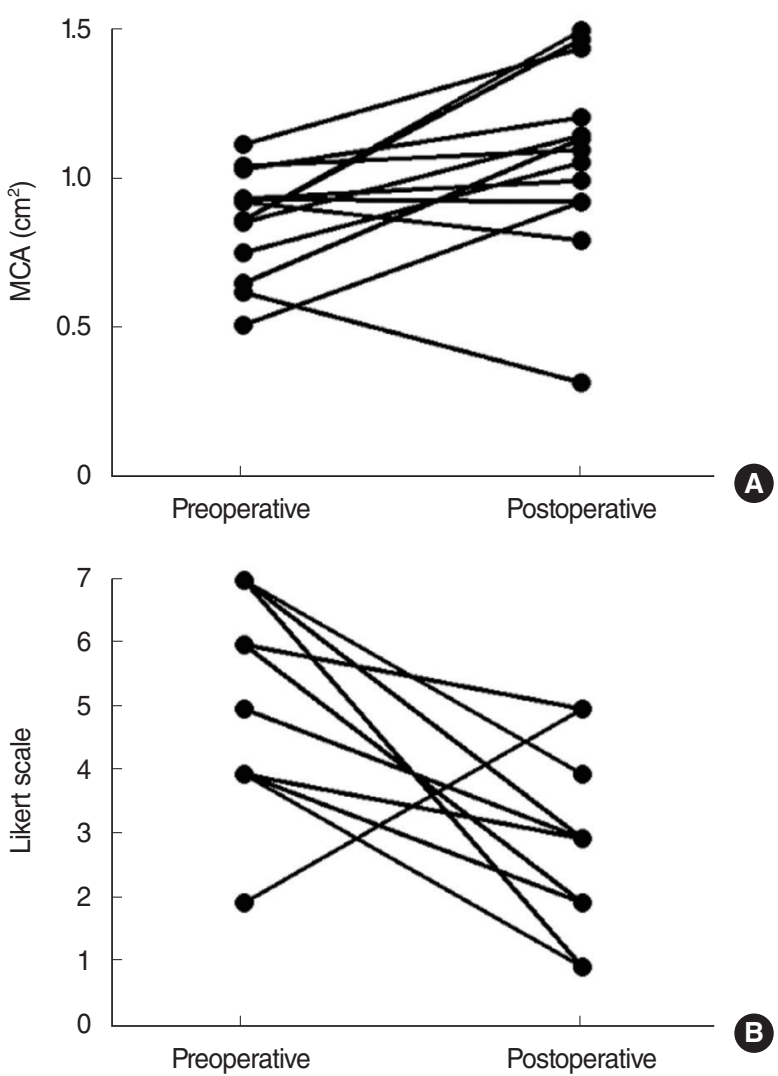

Fig. 4. Objective and subjective measurements of nasal obstruction. (A) Pre- and postoperative changes of acoustic rhinometry with minimal cross-sectional area $\left(\mathrm{MCA}, \mathrm{cm}^{2}\right)$. (B) Likert scale of nasal obstruction.

when comparing pre- and postoperative results, both postoperative values close to the ideal angles, respectively. The long-term results of 12 patients were $2.49^{\circ}\left(0.80^{\circ}-3.91^{\circ}\right)(P=0.015)$ for nasal tip deviation and $178.68^{\circ}\left(175.78^{\circ}-178.98^{\circ}\right)(P=0.002)$ for middle vault deviation (Table 2$)$. There were no significant differences between the immediate and long-term results $(P=$ 0.807 for nasal tip deviation and $P=0.242$ for middle vault deviation, respectively).

Two independent physicians evaluated the aesthetic outcome using the final results for each patient; complete correction in eight patients $(47.1 \%)$, minimally visible deviation in seven patients $(41.2 \%)$ and remaining residual deviation in two patients $(11.8 \%)$. Fig. 3 shows pre- and postoperative photos of complete correction patients.

Thirteen patients completed pre- and postoperative acoustic 
rhinometry. Pre- and postoperative MCAs of summation of the right and left sides were $0.86(0.28)$ and $1.07(0.39)$, respectively $(P=0.021)$ (Fig. 4A).

Fifteen patients answered about their nasal obstruction symptoms and the median score was improved from 6.0 (3.0) to 3.0 (3.0) $(P=0.004)$ (Fig. 4B). Among them, only one patient who had severe S-shaped septal deviation reported that nasal obstruction symptom was aggravated after surgery. There was one revision septoplasty and one repair surgery required for minimal septal perforation after the primary surgery.

\section{DISCUSSION}

Triangular resection of the ULC has a significant effect on the straightness and balance of the middle vault. The functional and aesthetic results of this new technique were satisfactory to both the surgeon and patients. Middle vault deviation, especially middle vault deviation angle, was significantly improved in all patients; only two patients had residual deviation. In addition, subjective nasal obstruction and the MCA of acoustic rhinometry were also alleviated. The main purpose of this procedure is to balance the ULCs. Asymmetry of the ULC in the deviation of the middle vault is accompanied with a widening and lengthening of one side of the ULC. Therefore, triangular resection might be an essential procedure if the size of the ULCs is dissimilar.

The spreader graft has been a common procedure for widening the nasal valve area or straightening the middle vault of the nose since Sheen [11] first introduced this technique. This type of graft is considered the gold standard for open roof deformity after dorsal hump removal. Since then, various modified methods of reduction rhinoplasty have been reported, including the spreader flap, autospreader graft, autospreader flap, and modified triangular spreader graft [12-15].

For straightening the dorsum, a spreader graft can restore an aesthetic line of the concave side or of both sides [16]. Due to the accompanying widening effect of a spreader graft, it is inevitable that the dorsum is widened in patients who have a large enough internal valve angle. Furthermore, a spreader graft has no consideration for the asymmetry of the ULC and balancing both sides, which is important for straightening the middle vault.

In the present study, a triangular resection was performed so as to only remove the surplus portion of the ULC; there were no influences on the dorsal width. The nasal bone of Asian noses is flatter and lower than that of Caucasian noses, and the associated ULC is wider [17,18]. Nasal obstruction caused by internal valve narrowing is an uncommon complication in Asian noses, and the effect of a spreader graft is vague [10].

Another disadvantage of a spreader graft is that it requires septal cartilage harvest; sometimes conchal or costal cartilage is required in cases of revision septoplasty or with a severely deviated septum [19]. If the harvesting of ear or rib cartilages is necessary, surgeons often worry about donor site morbidities; the associated procedures are also time-consuming and laborious. Spreader flaps have no requirement for cartilage harvesting, but one disadvantage of this method is that it can only be used in those who have adequate ULC height and rigidity [20]. For all these reasons, triangular resection of the ULC might be considered an adjunctive surgical option for correcting middle vault deviation. In addition, triangular resection may be combined with a spreader graft to balance the ULCs. If a spreader graft is used for the concave side of the middle vault, the ULC of the opposite side will require a triangular resection. In the case of a spreader flap, a unilateral spreader flap can be made with the wider side of the ULC and the folded portion in much the same manner as removing part of the triangular resection. In contrast, a bilateral spreader flap requires a triangular resection of any excessive ULC to achieve symmetry [20]. In some selected cases, triangular resection might be used alone and it can be substituent procedure of spreader graft or spreader flap.

The functional effect of spreader graft or flap on nasal valve area has been questionable and unestablished. Acoustic rhinometry and peak nasal inspiratory flow (PNIF) are commonly used methods to assess objective nasal obstruction. These measurements not only test the nasal valve area but also reflect the entire nasal cavity. Saedi et al. [13] evaluated the functional outcomes of spreader flaps with a randomized setting in Iranian patients and concluded that there was no significant difference of the MCA between the spreader flap and the control group. Xavier et al. [21] assessed nasal breathing with PNIF in patients who underwent rhinoplasty with spreader graft as well as in those without a spreader graft. PNIF increased in both groups, but the changes were not statistically different. Most patients in the present study underwent septoplasty simultaneously, and acoustic rhinometry changes were influenced by the septoplasty's effects. Septoplasty was performed simultaneously along with triangular resection of the ULC; although the postoperative result of the mean MCA increased and asymmetry of the nasal cavity's MCA improved, there was no statistical significance. In addition, no patients reported valve problems preoperatively, and no valve collapse was observed during surgery.

The authors evaluated subjective nasal obstruction using a patient-reported Likert scale; most patients experienced an improvement in their symptoms. Only one patient complained of nasal obstruction on the opposite side, which had been wider before the septoplasty. The reason was septal overcorrection, and the symptoms were alleviated after one month.

The limitations of this study include the short-term duration of follow-up and the variety of ancillary surgical procedures. It is difficult to identify the effect of triangular resection only; therefore, randomized clinical trials with a large population are warranted to better define the surgical effects. Although there 
was no complication in this pilot study, such as saddle nose or valve collapse, complications are possible when we handle the ULC and septum. Therefore, more participants and a long-term follow-up period are required for future studies.

Correcting middle vault deviation is surgically challenging and it has a risk of internal valve problem. Triangular resection of the ULC is a very simple and timesaving method for correcting middle vault deviation and balancing the ULCs, and results in good aesthetic and functional outcomes. This technique was also accompanied with a spreader graft to balance the ULCs.

\section{CONFLICT OF INTEREST}

No potential conflict of interest relevant to this article was reported.

\section{REFERENCES}

1. Constantinides MS, Adamson PA, Cole P. The long-term effects of open cosmetic septorhinoplasty on nasal air flow. Arch Otolaryngol Head Neck Surg. 1996 Jan;122(1):41-5.

2. Ozturan O. Techniques for the improvement of the internal nasal valve in functional-cosmetic nasal surgery. Acta Otolaryngol. 2000 Mar;120(2):312-5.

3. Potter JK. Correction of the crooked nose. Oral Maxillofac Surg Clin North Am. 2012 Feb;24(1):95-107.

4. Pontius AT, Leach JL Jr. New techniques for management of the crooked nose. Arch Facial Plast Surg. 2004 Jul-Aug;6(4):263-6.

5. Cerkes N. The crooked nose: principles of treatment. Aesthet Surg J. $2011 \mathrm{Feb} ; 31(2): 241-57$.

6. Kang JM, Nam ME, Dhong HJ, Kim HY, Chung SK, Kim JH. Modified mattress suturing technique for correcting the septal high dorsal deviation around the keystone area. Am J Rhinol Allergy. 2012 MayJun;26(3):227-32.

7. Okur E, Yildirim I, Aydogan B, Akif Kilic M. Outcome of surgery for crooked nose: an objective method of evaluation. Aesthetic Plast Surg.
2004 Jul-Aug;28(4):203-7.

8. Erdem T, Ozturan O. Objective measurement of the deviated nose and a review of surgical techniques for correction. Rhinology. 2008 Mar;46(1):56-61.

9. Zuo L, Jing S, Zhou C, Dai Z, Yang S, Sun B, et al. Tension-relaxing method-A simplified revision of the endoscopic septoplasty technique: for both aesthetic appearance and functionality. Am J Rhinol Allergy. 2015 Jul-Aug;29(4):e105-11.

10. Jin HR, Lee JY, Shin SO, Choi YS, Lee DW. Key maneuvers for successful correction of a deviated nose in Asians. Am J Rhinol. 2006 Nov-Dec;20(6):609-14

11. Sheen JH. Spreader graft: a method of reconstructing the roof of the middle nasal vault following rhinoplasty. Plast Reconstr Surg. 1984 Feb;73(2):230-9.

12. Yoo S, Most SP. Nasal airway preservation using the autospreader technique: analysis of outcomes using a disease-specific quality-oflife instrument. Arch Facial Plast Surg. 2011 Jul-Aug;13(4):231-3.

13. Saedi B, Amali A, Gharavis V, Yekta BG, Most SP. Spreader flaps do not change early functional outcomes in reduction rhinoplasty: a randomized control trial. Am J Rhinol Allergy. 2014 Jan-Feb;28(1): 70-4.

14. Moubayed SP, Most SP. The autospreader flap for midvault reconstruction following dorsal Hump resection. Facial Plast Surg. 2016 Feb;32(1):36-41.

15. Sahin MS, Ozmen OA. Early results and description of a new modification of spreader graft to enlarge nasal valve area: modified triangular spreader graft. J Craniofac Surg. 2016 Jun;27(4):839-42.

16. Kim L, Papel ID. Spreader grafts in functional rhinoplasty. Facial Plast Surg. 2016 Feb;32(1):29-35.

17. Jang YJ,Alfanta EM. Rhinoplasty in the Asian nose. Facial Plast Surg Clin North Am. 2014 Aug;22(3):357-77.

18. Li D, An Y,Yang X. An overview of Asian rhinoplasty. Ann Plast Surg. 2016 Feb;77 Suppl 1:S22-4.

19. Sirinoglu H, Yesiloglu N, Ersoy B. A new perspective for spreader graft use in severely deviated septum: is septal continuity an obligation for a stable and straight nasal septum? Facial Plast Surg. 2016 Aug; 32(4):460-8

20. Kovacevic M, Riedel F, Goksel A, Wurm J. Options for middle vault and dorsum restoration after hump removal in primary rhinoplasty. Facial Plast Surg. 2016 Aug;32(4):374-83.

21. Xavier R,Azeredo-Lopes S, Papoila A. Spreader grafts: functional or just aesthetical? Rhinology. 2015 Dec;53(4):332-9. 